\title{
Saccadic Eye Movement Related Potentials
}

\author{
F. JAGLA, M. JERGELOVÁ, I. RIEČANSKÝ \\ Institute of Normal and Pathological Physiology, Center of Excellence for Cardiovascular \\ Research, Slovak Academy of Sciences, Bratislava, Slovakia
}

Received June 6, 2007

Accepted September 10, 2007

\begin{abstract}
Summary
The saccadic eye movement related potentials (SEMRPs) enable to study brain mechanisms of the sensorimotor integration. SEMRPs provide insight into various cognitive mechanisms related to planning, programming, generation and execution of the saccadic eye movements. SEMRPs can be used to investigate pathophysiological mechanisms of several disorders of the central nervous system. Here we shortly summarize basic findings concerning the significance of SEMRP components, their relationship to the functional brain asymmetry and visual attention level as well as changes related to certain neuropsychological disorders.
\end{abstract}

\author{
Key words \\ EEG $\bullet$ Evoked potentials $\bullet$ Saccades $\bullet$ Attention $\bullet$ Laterality $\bullet$ Brain disorders
}

\section{Introduction}

Humans use rapid change of gaze direction to fix their line of sight onto a newly appearing object in the periphery of the visual field, called the visual grasp reflex by Hess et al. (1946). The rapid changes of the gaze fixation are subserved by the saccadic eye movements (SEMs) - rapid, short, ballistic, conjugate movements of eyes. SEMs may be elicited in a reflexive way to external stimuli but also voluntarily. Programming of SEMs is a complex cognitive process based on the integration of visual, acoustic, and somatosensory information and is influenced by cognitive demands.

As early as 1957 a sharp positive wave over the occipital cortex, which followed rapid eye movements, the so-called lambda wave, has been described in an native EEG by Green (1957). Saccadic eye movement related potentials (SEMRPs) - averaged potential changes time-locked to the onset of the saccades have been described some years later by Gaarder et al. (1964). SEMRPs recorded over the posterior parietal cortex may be essentially divided into two parts (time periods). The first part consists of potential changes preceding SEM, which are related to motor processes of SEM programming and preparation. The second part, which follows SEM, consists of the lambda complex reflecting mainly encoding of a new visual information (Fig. 1). At about 1-3 s before the SEM onset a pre-motion negativity (PMN) can be registered (Becker et al. 1972, Klostermann et al. 1994) over the occipital and posterior parietal areas. PMN is considered as an analogue of the readiness potential (Kornhuber and Deecke 1964) but also to reflect the activity related to nonspecific psychological processes. Premotion positivity (PMP) 
starting approximately 100-150 ms before the SEM onset is considered to be a correlate of the SEM motor program formulation (Armington 1978, Jagla and Zikmund 1994b). The maximal recruitment of the oculomotor muscle units at the beginning of the eye movement is reflected by so-called spike potential (SP) (Thickbroom and Mastaglia 1986) peaking several milliseconds after the onset of a saccade. Alternatively, it has been proposed that SP is generated from central sources (Weinstein et al. 1991). The most constant and pronounced component of the parietal SEMPRs is the positive lambda response (LR) peaking at 140-160 ms after the SEM onset. LR is a correlate of the input of a new visual information into the primary visual cortex. A detailed description of the lambda complex has been given by Marton et al. (1983). The shape of the lambda complex depends on the structure of the visual background (Morton and Cobb 1973), level of illumination (Gaarder et al. 1964), and also amplitude of the SEM (Yagi 1979).

Components of the SEMRPs recorded over (the) frontal oculomotor areas (frontal eye fields, FEFs) are less well understood. In our studies we have repeatedly described frontal potential changes related to SEMs lasting approximately $400 \mathrm{~ms}$, starting about 90-100 ms before the SEM onset and terminating about $300 \mathrm{~ms}$ after the SEM offset. The most prominent component of this complex is a negativity of short-duration-peaking at the time of the parietal lambda response (N3). We have hypothesized that N3 may be a sign of blocking an eye movement execution during the encoding the basic visual information from a new fixation (Jagla et al. 1994a). Everling et al. $(1998,2001)$ have pointed out that the preparatory cortical processes in the frontal lobe prior to a stimulus presentation have an important influence on the oculomotor performance.

We have further shown that the frontal SEMRPs are more frequently modulated by cognitive demands than the parietal ones. The evidence comes from tasks which interfered with the execution of visually guided saccades, such as a distraction of visual attention or mental arithmetic (Jergelová et al. 1996). Moreover, the frontal SEMRPs depend on the type of the saccadic eye movements (Evdokimidis et al. 1992). For example, there are marked differences between the SEMRPs by visually guided saccades comparing to antisaccades - SEMs executed in the direction opposite to the visual target (Jagla et al. 1996, McDowell and Clementz 2005, Brown et al. 2007). Frontal SEMRPs also reflect such internal states of the subject as the motivation (Evdokimidis et al. 1997).

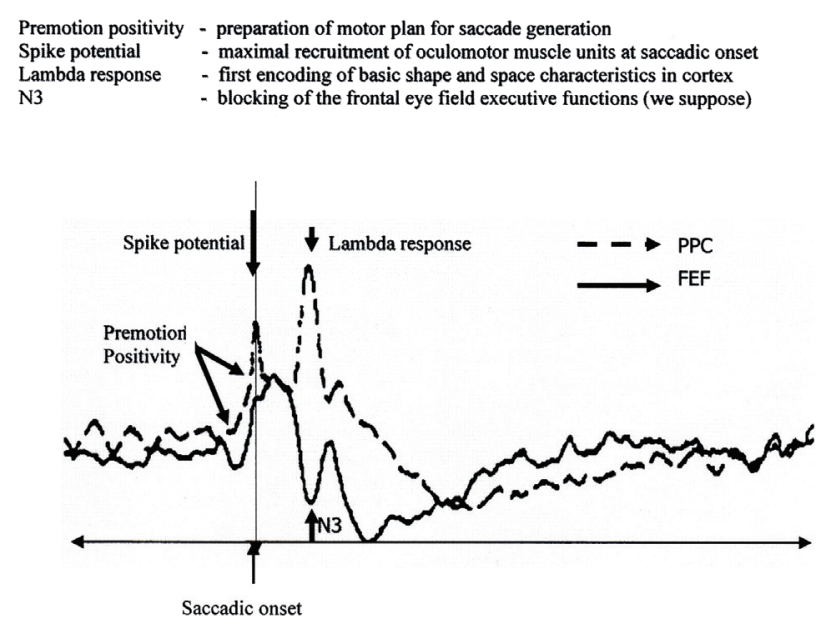

Fig. 1. Grand average SEMRPs from 30 healthy subjects recorded over the posterior parietal areas (PPC, dashed line) and over the frontal eye fields (FEF, solid line). For description of components see the text.

\section{SEMRPs, functional brain asymmetry and attention}

Lateralization of oculomotor functions has been discussed by several authors. Sava et al. (1988) have suggested that the right hemisphere is dominant for the programming of eye movements of right-handers. Based on analysis of SEMRP components we have found that the right hemisphere is preferentially engaged with the generation of leftward saccades. PMP and SP over the right hemisphere were of shorter latencies and lower amplitudes with SEMs directed to the left. We have interpreted the lowering of the amplitude as a sign of a specialization in sense of high processing efficiency (Jagla and Zikmund 1989).

Moreover, there is a firm relationship between the functional brain asymmetry and the SEMs accuracy. In healthy subjects $95 \%$ of SEMs of the simple visually guided saccades are accurate and for visual targets separated by $10^{\circ}$ the error does not exceed $0.5^{\circ}$. We have repeatedly shown that in right-handers the SEMs to the left are more accurate than the SEMs to the right (Jagla et al. 1976, 1992). Furthermore, we have found that the latency of corrective saccades depends on the functional brain asymmetry too. The shortest reaction time has been found with leftward directed corrective saccades from the right to the center of the screen, that is, with the corrective SEMs after the undershooting the visual target with the main saccade directed from the right periphery to the center of the screen (Jagla and Zikmund 1981). We have also found a remarkable difference between the accuracy of upward and 
downward SEMs (Jagla and Zikmund 1991, 1994). The inaccuracy of upward saccades is low and comparable to that of horizontal SEMs. In contrast, downward SEMs are more inaccurate in terms of both frequency and positional error. This implicates that the SEMRPs with SEMs to different directions should be analyzed separately and the trials containing corrective saccades should be omitted from the recordings. Moiseeva et al. (1999) have reported a complex relationship between the oculomotor performance, presaccadic potentials and lateralized motor eye dominance.

The accuracy of SEMs further depends on the regularity of intervals between presentations of visual targets. With the consecutive visual targets switched on and off at regular intervals the stereotyped presentation of visual stimuli allows the subject not only to predict the time of their appearance but also their location within the visual field. This enables the subject to trigger the SEMs rather automatically leading to a gradual decrease in attention paid to the visual fixation task. In such a situation the SEMRPs components become less expressed as opposed to the situation with irregular time intervals between consecutive gaze fixations. When a subject cannot anticipate the appearance of a visual stimulus the readiness to react with a SEM must be maintained for the whole time of the experimental task. This is reflected by enhanced preparatory components of the SEMRPs preceding the SEM onset (Jagla et al. 1994b).

Distraction of visual attention during the fixation task (e.g. by means of interfering mental activity) leads to a prolongation of SEM preparation, which is mirrored by longer duration of PMN and PMP (Fig. 2). Moreover, the maximal recruitment of the oculomotor muscle units at the onset of a SEM and hence SP of the SEMRP is delayed (Jagla et al. 1999). Recent findings of Brignani et al (2007), who have analyzed event-related EEG spectral changes during the preparation and execution of SEMs, support the idea that the eye movement planning is linked with covert orienting of spatial attention as well as the notion of the right hemisphere dominance in the directing attention. The findings thus indicate that nonspecific cortical processing occurs also within functionally specialized neuronal networks. The SEM elicited by a visual target requires a co-ordination among sensory and association areas enabling the brain to register and analyze the stimulus, and motor areas preparing the motor program and response execution. These distributed neuronal structures form networks engaged in focusing attention and regulation of behavioral response (Jagla et al. 2006).
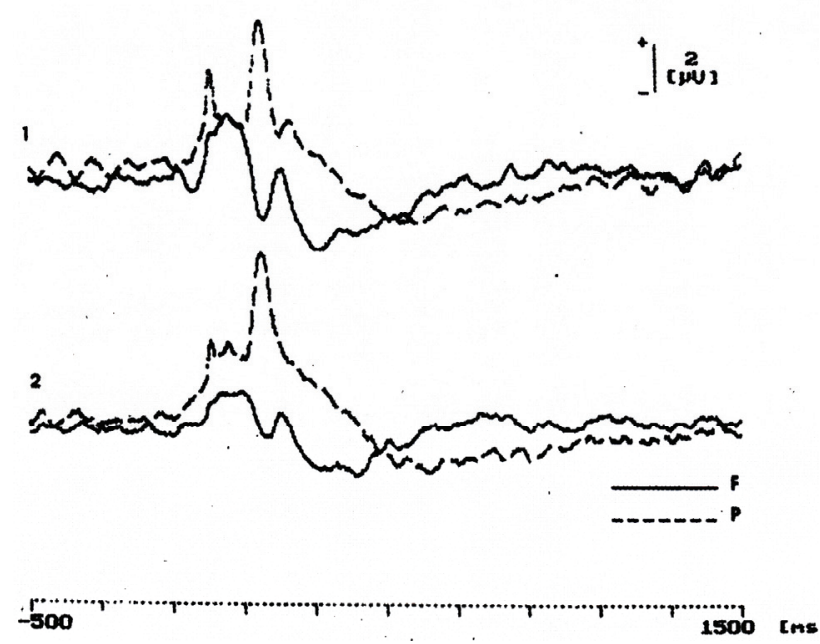

Fig. 2. The effect of visual attention on SEMRPs. The upper curves (1) are the same as in Fig.1. The lower curves (2) are grand average SEMRPs during focusing attention to the half field opposite to the visual target appearance. Note the marked changes in the overall amplitudes of frontal SEMRPs (solid line) as well as of parietal SP (dashed line).

\section{SEMRPs and brain disorders}

Several functional neuroimaging studies have revealed a decreased functioning in the frontal, parietal and temporal lobes during affective disorders (Soares and Mann 1997). It has been repeatedly found that bipolar disorder and depression are associated with a decrease in regional cerebral blood flow and hypometabolism in the prefrontal cortex. Sweeney and co-workers stressed the role of prefrontal and cerebellar abnormalities in major depression in connection with specific changes of various oculomotor parameters. In a well documented study (Sweeney et al. 1998) these authors have demonstrated increased rates of saccadic intrusions during the visual fixation, dysmetric visually guided saccades, and increased rates of response suppression errors on an antisaccade task of depressed patients.

In one of our studies (Jagla et al. 2000) a group of patients with a depressive symptomatology has been examined. We have found an increased number of dysmetric visually guided saccades (up to three times in comparison with healthy controls). Moreover, we have found a significant increase in PMP and SP latencies in the SEMRPs from posterior parietal areas. There was no difference in the latency of LR as compared to the healthy controls. SEMRPs recorded over the frontal eye fields showed a prolonged overall duration and the latency of N3 component was delayed (Fig. 3). On the other hand, the functional brain asymmetry as reflected 
by SEMRPs was not altered in the patient group. We do not expect that our results were due to psychotropic medication. Rather we suppose that the depression is accompanied by changes in attention, which is focused to emotions and mental processes of the patients. The enhanced number of dysmetric saccades and the changes of SEMRPs support this idea.

SEMRPs have been further used to study pathophysiological mechanisms of anxiety disorders, especially the panic disorder (PD). The neurobiological theories attempting to clarify the etiopathogenesis of the PD emphasize mainly changes in the brain biochemistry and point to abnormalities in the function of several neurotransmitters within the brain stem neuronal circuits, limbic system and fronto-temporal cortical areas (see e.g. Goddard and Charney 1997). Since the oculomotor nuclei are located in the lower brain stem we decided to analyze changes in the visual-oculomotor integrations in PD. We have examined PD outpatients within the interparoxysmal period, more than 1 year from the last panic attack. The patients took no specific medications for more than 6 months and worked regularly in their occupations. In the patient group we have found a high intrusion of corrective saccades, which affected the recorded EEG to such extent that the SEMRPs could not be reliably evaluated (Jagla et al. 2003). We have further investigated ERP locked to voluntary blocking of reflexive saccades. Trials requiring the withdrawal of the reflexive saccade were randomly interleaved with trials of visually guided SEMs. Blocking of saccade execution thus yielded a typical cognitive P3 wave. In PD patients significantly higher P3 latency has been found in comparison to healthy subjects (Jagla et al. 2005). The cognitive $\mathrm{P} 3$ wave is a multicomponent phenomenon and reflects various processes. In our examinations this wave was markedly influenced by the inability of panic patients to filter out the irrelevant stimuli. The increase in P3 latency in panic patients supports the view that $\mathrm{P} 3$ represents an index of stimulus processing on a higher level of the CNS hierarchy connected quite closely with the contextual evaluation of stimuli having to be attended. We remind that the abnormalities of oculomotor regulations in PD patients are not restricted to SEMs. We have also found deficits in the optokinetic nystagmus, in particular a difficulty to follow the motion of visual targets at higher speeds (Jagla et al. 2002).

Results obtained in patients suffering from depression as well as panic disorder patients suggest that the SEMRPs cannot be taken as specific

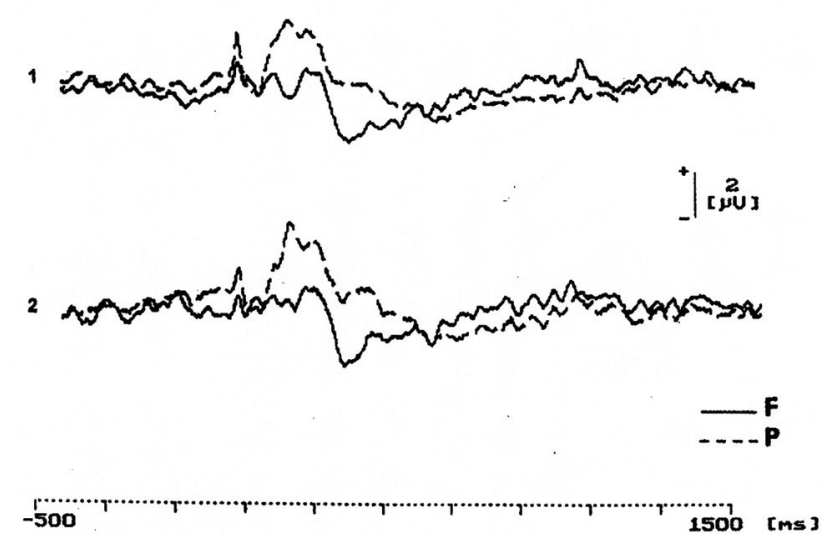

Fig. 3. SEMRPs in depression. The upper curves (1) illustrate SEMRPs grand averages from healthy subjects (dashed line: parietal cortex, solid line: frontal cortex). The lower curves (2) are recorded from patients suffering from depression. Note the difference in frontal amplitudes and in the morphology of lambda complex as well as the marked changes in frontal SEMRPs.

electrophysiological correlates of given disorders. Nevertheless, we suggest including them into the battery of clinical electrophysiological tests since they are able to reveal persistent changes in brain function also in clinically asymptomatic cases.

While several studies have analyzed and described abnormalities of SEMs in schizophrenia, the reports on electrophysiological signatures of the altered SEM generation are sparse. Disturbance of SEMs in schizophrenia includes increased saccadic latencies, lower spatial accuracy, and lower peak velocity (Hutton et al. 2001). The deficits are in general more pronounced for internally guided saccades (such as antisaccades and memory-guided saccades) than for reflexive visually guided saccades (Fukushima et al. 1988, Muller et al. 1999). Slavutskaya et al. (2005) (have) measured EEG during saccade execution in acute schizophrenic patients. However, these were not true SEMRPs since the averaging was not time-locked to the onset of a saccade but to the onset of a visual target. The authors have found a higher number of anticipatory saccades along with decreased amplitude and different topography of premotion negativity in the patient group. The changes were attributed to deficits of frontal cortical fields in schizophrenic patients. Using fMRI, McDowell and Clementz (2001) have found an abnormally low dorsolateral prefrontal cortex activity during the execution of antisaccades in schizophrenic subjects and have related this finding to spatio-temporal patterns of brain activation derived from SEMRPs. 


\section{Conclusions}

The visual-oculomotor integration represents the tightest and the most finely tuned kind of the/a sensorimotor integration. Studying this integration involves analysis of ,peripheral“ (oculomotor) and „central“" (electroencephalographic) correlates along with subjective reports given by the subjects taking part in the examination. Thus SEMRPs are an useful tool for assessment of processes that underlie SEM generation. It can be expected that future studies will reveal more details about the function of the oculomotor system. Further patient studies employing SEMRPs could yield a better understanding of pathophysiological mechanisms of neuropsychiatric disorders. Novel insights can further come from the use of alternative techniques of EEG data analysis (e.g. Bob et al. 2006a,b). There are also indications that oculomotor tests and the analysis of the central correlates of the oculomotor activity including SEMRPs may be used for diagnostic purposes and for assessing of therapeutic effects of a neuropsychopharmacological treatment.

\section{Acknowledgements}

This work was partially supported by the scientific grant agency of the Slovak Ministry of Education and Slovak Academy of Sciences VEGA (project No. 2/5049/27).

\section{References}

ARMINGTON JC: Potentials that precede small saccades. In: Visual Psychophysics and Physiology, JC ARMINGTON (ed), Academic Press, New York, 1978, pp 363-372.

BECKER W, HOEHNE O, IWASE K, KORNHUBER HH: Bereitschaftspotential, praemotorische Positivierung und andere Hirnpotentiale bei sakkadischen Augenbewegungen. Vision Res 9: 421-436, 1972.

BOB P, ŠUSTA M, PROCHÁZKOVÁ-VEČEŘOVÁ A, KUKLETA M, PAVLÁT J, JAGLA F, RABOCH J: Limbic irritability and chaotic neural response during conflicting Stroop task in the patients with unipolar depression. Physiol Res 55 (Suppl 1): S107-S112, 2006 a.

BOB P, KUKLETA M, RIEČANSKÝ I, ŠUSTA M, KUKUMBERG P, JAGLA F: Chaotic EEG patterns during recall of stressful memory related to panic attack. Physiol Res 55 (Suppl 1): S113-S119, 2006b.

BRIGNANI D, MAIOLI C, ROSSINI PM, MINIUSSI C: Event-related power modulations of brain activity preceding visually guided saccades. Brain Res 1136: 122-131, 2007.

BROWN MR, VILIS T, EVERLING S: Frontoparietal activation with preparation for antisaccades. J Neurophysiol 98: 1751-1762, 2007.

CLEMENTZ BA, MCDOWELL JE, STEWART SE: Timing and magnitude of frontal activity differentiates refixation and anti-saccade performance. NeuroReport 12: 1863-1868, 2001.

EVDOKIMIDIS I, MERGNER T, LUCKING CH: Dependence of presaccadic potentials on the type of the saccadic eye movements. Electroenceph Clin Neurophysiol 83: 179-191, 1992.

EVDOKIMIDIS I, CONSTANTINIDIS TS, GOURTZELIDIS P, LIAKOPOULOS C, PAPAGEORGIOU C: Changes of presaccadic cortical activity when performing horizontal, visually guided saccades. Electroenceph Clin Neurophysiol 102: 256-260, 1997.

EVERLING S, SPANTENKOW A, KRAPPMANN P, FLOHR H: Event-related potentials associated with correct and incorrect responses in a cued antisaccade task. Exp Brain Res 118: 27-34, 1998.

EVERLING S, MATTHEWS A, FLOHR H: Prestimulus cortical potentials predict the performance in a saccadic distractor paradigm. Clin Neurophysiol 112: 1088-1095, 2001.

FUKUSHIMA J, FUKUSHIMA K, CHIBA T, TANAKA S, YAMASHITA I, KATO M: Disturbances of voluntary control of saccadic eye movements in schizophrenic patients. Biol Psychiat 23: 670-677, 1988.

GAARDER K, KRAUSKOPF K, GRAF V, KROPFL W, ARMINGTON JC: Averaged brain activity following saccadic eye movement. Science 146: 1481-1483, 1964.

GODDARD AW, CHARNEY DS: Toward an integrated neurobiology of panic disorder. J Clin Psychiatry 58: 4-11, 1997.

GREEN J: Some observations on lambda waves and peripheral stimulation. Electroenceph Clin Neurophysiol 9: 691704, 1957. 
HESS WR, BURGI S, BUCHER V: Motor function of tectal and tegmental area. Monatschr Psychiatr Neurol 112: 1$52,1946$.

HUTTON SB, CUTHBERT I, CRAWFORD TJ, KENNARD C, BARNES TR, JOYCE EM: Saccadic hypometria in drug-naïve and drug treated schizophrenic patients: a working memory deficit? Psychophysiology 38: 125-132, 2001.

JAGLA F, ZIKMUND V: Saccadic eye movements and cerebral hemisphere dominance.(in Slovak) Čs Oftal 37: 132$137,1981$.

JAGLA F, ZIKMUND V: Lambda responses are related to functional asymmetry of the brain. Int J Psychophysiol 7: 245-246, 1989.

JAGLA F, ZIKMUND V: Saccadic eye movement related potentials depend on direction of saccades. Electroenceph Clin Neurophysiol 78: 31P, 1991.

JAGLA F, ZIKMUND V: Differences in eye movement related potentials with visually triggered horizontal and vertical saccades. In: Visual and Oculomotor Function, Advances in Eye Movement Research, G D' YDEWALLE, J VAN RENSBERGEN (eds), North-Holland, Amsterdam, 1994, pp 19-30.

JAGLA F, YAKIMOFF NA, ZIKMUND V, MITRANI L, MATEEFF S: Hemispheric dominance and saccadic eye movements. Physiol Bohemoslov 25: 445-446, 1976.

JAGLA F, ZIKMUND V, MASHONKINA TR, YAKIMOFF NA: Accuracy of saccadic eye movements depends on their horizontal and vertical direction. (in Slovak) Bratisl Lek Listy 93: 287-290, 1992.

JAGLA F, ZIKMUND V, FINDLAY JM: The effect of visual attention upon programming of saccadic eye movements. Studia Psychol 36: 350-253, 1994a.

JAGLA F, ZIKMUND V, KUNDRÁT J: Differences in saccadic eye movement related potentials under regular and irregular intervals of visual stimulation. Physiol Res 43: 229-232, $1994 \mathrm{~b}$.

JAGLA F, ZIKMUND V, FINDLAY JM: Changes in oculomotor evoked potentials in antisaccadic task. Homeostasis Health Disease 37: 269-270, 1996.

JAGLA F, JERGELOVÁ M, ZIKMUND V: Visual fixation and oculomotor evoked potential changes during the divided attention task. Homeostasis Health Disease 39: 117-118, 1999.

JAGLA F, ZIKMUND V, ŽUCHA I: Eye movements and eye movement related brain potentials in patients with symptoms of depression. Homeostasis Health Disease 40: 71-75, 2000.

JAGLA F, KUKUMBERG P, JERGELOVÁ M: Central and peripheral oculomotor manifestations in panic disorder. In: Neurophysiology and Behavioural Intervention in Psychosomatics, Stress Disorders and Health Promotion, Proceeding of the International CIANS Conference 2001, GF GOLDWURM, F COLOMBO, S MASARAKI (eds), CIANS, Milano, 2002, pp 171-176.

JAGLA F, JERGELOVÁ M, CIRNECI D, KUKUMBERG P: Oculomotor and evoked potential changes in panic and depressive patients. Homeostasis Health Disease 42: 145-147, 2003.

JAGLA F, JERGELOVÁ M, ZIKMUND V: Movement related potentials with execution, reorganization and blocking of saccades. In: International CIANS Conference 2005, Book of Abstracts, F JAGLA, I RIEČANSKÝ (eds), Ústav normálnej a patologickej fyziológie SAV, Bratislava, ISBN 80-969339-2-2, 2005, p 47.

JAGLA F, JERGELOVÁ M, RIEČANSKÝ I: Sensorimotor integration in health and disease. In: Selected Diseases of Civilisation: Basic Mechanisms and Clinical Implications, O PECHÁŇOVÁ, F JAGLA (eds), Univerzita Komenského, Bratislava, 2006, pp 13-40.

JERGELOVÁ M, JAGLA F, ZIKMUND V: Modulation of sensorimotor integrations by voluntary motor acts and their representation: electrophysiological manifestations. Homeostasis Health Disease 37: 272-273, 1996.

KLOSTERMANN W, KÖMPF D, HEIDE W, VERLEGER R, WAUSCHKUHN B, SEYFERT T: The presaccadic cortical negativity prior to self-paced saccades with and without visual guidance. Electroenceph Clin Neurophysiol 91: 219-228, 1994.

KORNHUBER HH, DEECKE L: Hirnpotential-aenderungen beim Menschen vor und nach Wilkuerbewegungen, dargestellt mit Magnetband-speicherung und Rueckwartsanalyse. Pflueger's Arch 281: 52, 1964. 
MARTON M, SZIRTES J, DONAUER N: A comparative study of averaged lambda potentials in man and monkey. In: Psychophysiology 1980, Memory, Motivation and Event-Related Potentials in Mental Operations, R SINZ, MR ROSENZWEIG (eds), Elsevier, New York, 1983, pp 279-289.

MCDOWELL JE, CLEMENTZ BA: Behavioral and brain imaging studies of saccadic performance in schizophrenia. Biol Psychol 57: 5-22, 2001.

MOISEEVA VV, SLAVUTSKAIA MV, SHULGOVSKII VV: The effect of the visual stimulation on the leading and nonleading eye on the value of saccadic latency period and on the peak latency of rapid presaccadic potentials. Zh Vyssh Nerv Dejat Im IP Pavlova 49: 113-117, 1999.

MORTON HB, COBB WA: The effect of eye movements on visual evoked responses in man. In: The Oculomotor System and Brain Functions, V ZIKMUND (ed), Butterworths, London, 1973, pp 105-115.

MÜLLER N, RIEDEL M, EGGERT T, STRAUBE A: Internally and externally guided voluntary saccades in unmedicated and medicated schizophrenic patients. Part II. Saccadic latency, gain, and fixation suppression errors. Eur Arch Psychiatry Clin Neurosci 249: 7-14, 1999.

SAVA D, LIOTTI M, RIZZOLATTI G: Right hemisphere superiority for programming oculomotion: evidence from simple reaction time experiments. Neuropsychologia 26: 201-211, 1988.

SLAVUTSKAYA MV, KIRENSKAJA AV, NOVOTOTSKII-VLASOV VYU, SHULGOVSKII VV, KOZLOVSKAJA IB: Slow cortical potentials preceding visually guided saccades in schizophrenics. Human Physiol 31: 545-553, 2005.

SOARES JC, MANN JJ: The anatomy of mood disorders - review of structural neuroimaging studies. Biol Psychiat 41: 86-106, 1997.

SWEENEY JA, STROJWAS MH, MANN JJ, THASE ME: Prefrontal and cerebellar abnormalities in major depression: evidence from oculomotor studies. Psychiat Res 43: 584-594, 1998.

WEINSTEIN JM, BALABAN CD, VERHOEVE JN: Directional tuning of the human presaccadic spike potential. Brain Res 543: 243-250, 1991.

YAGI A: Saccadic size and lambda complex in man. Physiol Psychol 7: 370-376, 1979.

\section{Corresponding author}

Fedor Jagla, Ústav normálnej a patologickej fyziológie SAV, Sienkiewiczova 1, 81371 Bratislava, Slovenská Republika. Fax: +421 25296 8516. E-mail: fedor.jagla@savba.sk 